\title{
Global economic burden of schizophrenia: letter in response
}

This article was published in the following Dove Press journal:

Neuropsychiatric Disease and Treatment

5 December 2016

Number of times this article has been viewed

\author{
Amanda L Neil' \\ Vaughan J Carr ${ }^{2,3}$
}

'Menzies Institute for Medical Research, University of Tasmania, Hobart, Tasmania, ${ }^{2}$ Research Unit for Schizophrenia Epidemiology, School of Psychiatry, University of New South Wales, Sydney, New South Wales, ${ }^{3}$ Department of Psychiatry, School of Clinical Sciences, Monash University, Melbourne, Victoria, Australia
Correspondence: Amanda L Neil Menzies Institute for Medical Research, University of Tasmania, 17 Liverpool St, Hobart, Tasmania 7000, Australia

Tel +6I 362264640

Email amanda.neil@utas.edu.au

\section{Dear editor}

In reference to the recent systematic review by Chong et al $^{1}$ on cost-of-illness studies in schizophrenia, we seek to highlight the limited scope and apparent inconsistencies embedded within this review. The review utilizes the term schizophrenia alone as the identifying disorder-related variable within its search strategy. Schizophrenia is the prototypical and most prevalent among the psychotic disorders, and schizophrenia is certainly used as a generic term in reference to the "schizophrenia-related disorders", International Classification of Diseases (ICD)-10 codes F20-F29. The most wellknown example of such use is in the Global Burden of Disease studies..$^{2-4}$ However, the reliance on this term as being all-inclusive is diminishing, as reflected in the chapter heading change from Diagnostic and Statistical Manual of Mental Disorders (DSM)-IV to DSM-V, namely "Schizophrenia and Other Psychotic Disorders" to "Schizophrenia Spectrum and Other Psychotic Disorders". Further, the overarching term psychotic disorders are increasingly being used in the recognition of the substantial clinical, neuropsychological, neuroimaging, and genetic overlap between disorders within this group.

Chong et $\mathrm{al}^{1}$ review identifies one of our cost-of-illness studies pertaining to schizophrenia and other psychoses Carr et $a l,{ }^{5}$ but not the other Neil et al ${ }^{6}$ which refers to psychotic disorders within its title and abstract. Regardless, both studies encompass equivalent populations, with the difference that some results are provided by major ICD-10 diagnostic category in the earlier study by Carr et al. ${ }^{5}$ As there is no reference to, or discussion of disease classifications, in either the determination of the search strategy or the populations included in the reviewed studies of Chong et al, ${ }^{1}$ we are unable to comment on the comparability of the national cost comparisons made within the review.

In regard to the characterization of Carr et $\mathrm{al}^{5}$ within the review, we note the following qualifications. This analysis was primarily based on resource use assessed through interview of 980 individuals with psychosis, not through published literature, and with unit prices determined with reference to published literature. While the individuals were ascertained through a census of four urban locations, national prevalence was established, and national costs determined on this basis. Thus our paper of 2003 ought to have been incorporated in the national costs comparison, with estimates provided for both psychosis and schizophrenia (F20). As noted within the review, our study was one of the only three that considered total costs in relation to gross domestic product. We also noted that productivity losses due to suicide were separately estimated within the context of the analysis, although excluded from the total costs we presented. 
Finally, we are uncertain as to what is encompassed by "direct nonmedical suicide related costs" in the study by Chong et al, ${ }^{1}$ as suicide-related costs would normally be assessed as indirect costs. Furthermore, the inclusion of legal and law enforcement costs under indirect costs is not consistent with the usual definition which pertains, as specified by the authors, to productivity losses.

\section{Disclosure}

The authors report no conflicts of interest in this communication.

\section{References}

1. Chong HY, Teoh SL, Wu DB, Kotirum S, Chiou CF, Chaiyakunapruk N. Global economic burden of schizophrenia: a systematic review. Neuropsychiatr Dis Treat. 2016;12:357-373.
2. World Health Organization. The Global Burden of Disease: 2004 Update. Geneva, Switzerland: World Health Organization; 2008.

3. Whiteford HA, Degenhardt L, Rehm J, et al. Global burden of disease attributable to mental and substance use disorders: findings from the Global Burden of Disease Study 2010. Lancet. 2013;382(9904):1575-1586.

4. GBD 2015 Mortality and Causes of Death Collaborators. Global, regional, and national life expectancy, all-cause mortality, and cause-specific mortality for 249 causes of death, 1980-2015: a systematic analysis for the Global Burden of Disease Study 2015. Lancet. 2016;388(10053): $1459-1544$.

5. Carr V, Neil A, Halpin S, Holmes S, Lewin T. Costs of schizophrenia and other psychoses in urban Australia: findings from the low prevalence (psychotic) disorders study. Aust N Z J Psychiatry. 2003;37(1):31-40.

6. Neil AL, Carr VJ, Mihalopoulos C, Mackinnon A, Morgan VA. Costs of psychosis in 2010: findings from the second Australian National Survey of Psychosis. Aust N Z J Psychiatry. 2014;48(2):169-182. 


\section{Authors' reply \\ Huey Yi Chong' \\ Siew Li Teoh' \\ David Bin-Chia Wu' \\ Chiun-Fang Chiou ${ }^{2}$ \\ Nathorn Chaiyakunapruk ${ }^{1,3-5}$}

'School of Pharmacy, Monash University Malaysia, Selangor, Malaysia; 'Janssen Pharmaceutical Companies Asia Pacific, Singapore; ${ }^{3}$ Center of Pharmaceutical Outcomes Research (CPOR), Department of Pharmacy Practice, Faculty of Pharmaceutical Sciences, Naresuan University, Phitsanulok, Thailand; ${ }^{4}$ School of Pharmacy, University of Wisconsin, Madison, USA; ${ }^{5}$ School of Population Health, University of Queensland, Brisbane, Australia

Correspondence: Nathorn Chaiyakunapruk

School of Pharmacy, Monash University Malaysia, Jalan Lagoon Selatan, 46I50 Bandar Sunway, Selangor, Malaysia

Email nathorn.chaiyakunapruk@monash.edu

\section{Dear editor}

We thank Dr Neil and Professor Carr for their comments regarding our published systematic review "Global economic burden of schizophrenia: a systematic review". "We would like to address and clarify issues raised in their letter.

The authors made a good point related the absence of "psychotic disorders" in our review. Although the suggested term is increasingly recognized, it encompasses diverse disorders including schizophrenia, other psychotic disorders, and schizotypal (personality) disorder, etc. ${ }^{2}$ Owing to the fact that our review mainly focused specifically on schizophrenia, we included studies that estimated economic burden among patients with a diagnosis of schizophrenia, therefore the inclusion of this broader term "psychotic disorders" defeats the purpose of our review. We would like to argue that our search was comprehensive enough to capture all studies reported on the economic burden of schizophrenia, considering the rare use of the clinically specific term, as reckoned by the authors, in any economic burden study. In addition, the study by Neil et $\mathrm{al}^{3}$ was not identified due to the limitation of our search to title or abstract. Given that an overall cost of psychosis was estimated in Neil et al, ${ }^{3}$ it would be excluded, if identified, as it did not fulfill our predefined eligibility criteria.

The authors assert the misclassification of data sources used in their study, ${ }^{4}$ followed by its exclusion in the national cost comparison we performed. Since there was no actual interview conducted in Carr et al, ${ }^{4}$ they relied on data from the Low Prevalence Disorder Study (LPDS) in a related publication by Carr et al, ${ }^{5}$ such data source was classified as "literature" regardless of the methodology used in the cited publication. This was indicated in the definition of data sources in our review. In addition, it is clear that the annual cost of psychosis for the Australian urban population was estimated and reported. This estimate may fall short in reflecting the national cost of schizophrenia in Australia, leading to its omission in the national cost comparison.

The authors question the categorization of suicide-related cost and "legal and law enforcement costs". We agree that suicide-related cost is usually seen as the indirect cost, corresponding to the productivity loss due to premature death. However, this norm is potentially an underestimation whereby direct nonmedical cost due to suicide is often neglected. In our review, only two included studies ${ }^{6,7}$ estimated this cost due to funeral services and investigational costs in any suicide cases. This was indeed highlighted in our discussion to call for the estimation of special cost components related to schizophrenia in future economic burden studies. While it remains unclear on the categorization of "legal and law enforcement costs", this inconsistency was noted within the included studies in our review. Similar ambiguity was reported in Ascher-Svanum et al. ${ }^{8}$ Based on the definition by Insel, ${ }^{9}$ these costs were categorized under indirect cost. However, we acknowledge this limitation, therefore highlighting that there is a strong need for a guidance document in both conduct and reporting of economic burden studies in our review. In addition, we noted an error in our review and we would like to take this opportunity to correct it - we referred to Insel ${ }^{9}$ for the categorization of incarceration cost, instead of Modi et al (reference 27 in our original list). ${ }^{10}$

Overall, the issues highlighted by Neil and Carr were pertinent. Our review is useful as it provides a summary of methodology used, attributes to data availability and accessibility, methodology feasibility, and practicality. Based on the large volume of data extracted from 56 studies included in our review, we have presented valid findings related to the schizophrenia - its economic burden and methods used to estimate the burden.

\section{Disclosure}

$\mathrm{NC}$ and DBCW received financial support from Janssen. CFC is an employee of Janssen. Other authors report no conflicts of interest in this communication.

\section{References}

1. Chong HY, Teoh SL, Wu DB, Kotirum S, Chiou CF, Chaiyakunapruk N. Global economic burden of schizophrenia: a systematic review. Neuropsychiatr Dis Treat. 2016;12:357-373.

2. American Psychiatric Association. Diagnostic and Statistical Manual of Mental Disorders 5th Ed. Washington, DC: American Psychiatric Association; 2013.

3. Neil AL, Carr VJ, Mihalopoulos C, Mackinnon A, Morgan VA. Costs of psychosis in 2010: Findings from the second Australian National Survey of Psychosis. Aust N Z J Psychiatry. 2014;48(2):169-182. 
4. Carr VJ, Neil AL, Halpin SA, Holmes S, Lewin TJ. Costs of schizophrenia and other psychoses in urban Australia: Findings from the Low Prevalence (Psychotic) Disorders Study. Aust N Z J Psychiatry. 2003;37(1):31-40.

5. Carr VJ, Johnston PJ, Lewin TJ, Rajkumar S, Carter GL, Issakidis C. Patterns of service use among persons with schizophrenia and other psychotic disorders. Psychiatr Serv. 2003;54(2):226-235.

6. Goeree R, Farahati F, Burke N, et al. The economic burden of schizophrenia in Canada in 2004. Curr Med Res Opin. 2005;21(12): 2017-2028.
7. Wyatt RJ, Henter I, Leary MC, Taylor E. An economic evaluation of schizophrenia - 1991. Soc Psychiatry Psychiatr Epidemiol. 1995; 30(5):196-205.

8. Ascher-Svanum H, Nyhuis AW, Faries DE, Ball DE, Kinon BJ. Involvement in the US criminal justice system and cost implications for persons treated for schizophrenia. BMC Psychiatry. 2010;10.

9. Insel TR. Assessing the economic costs of serious mental illness. Am J Psychiatry. 2008;165(6):663-665.

10. Modi P, Suvarna K, Cooper GJ. Images in cardiology. Descending thoracic aortic aneurysm in rheumatoid arthritis. Heart. 2000;84(2):12.

Dove Medical Press encourages responsible, free and frank academic debate. The content of the Neuropsychiatric Disease and Treatment 'letters to the editor' section does not necessarily represent the views of Dove Medical Press, its officers, agents, employees, related entities or the Neuropsychiatric Disease and Treatment editors. While all reasonable steps have been taken to confirm the content of each letter, Dove Medical Press accepts no liability in respect of the content of any letter, nor is it responsible for the content and accuracy of any letter to the editor.

\section{Publish your work in this journal}

Neuropsychiatric Disease and Treatment is an international, peerreviewed journal of clinical therapeutics and pharmacology focusing on concise rapid reporting of clinical or pre-clinical studies on a range of neuropsychiatric and neurological disorders. This journal is indexed on PubMed Central, the 'PsycINFO' database and CAS, and is the official journal of The International Neuropsychiatric Association (INA). The manuscript management system is completely online and includes a very quick and fair peer-review system, which is all easy to use. Visit http://www.dovepress.com/testimonials.php to read real quotes from published authors. 